\title{
Appraising Issues on Reproductive Health in ASEAN; Focusing Efforts Towards Indexing JAFES
}

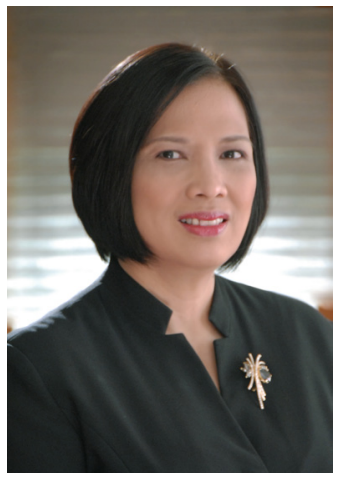

The Asian perspective on fertility, reproduction and pregnancy is broad, owing to the varied cultural and social nuances on this phase of a woman's life and her family.

This issue of JAFES tackles exactly these sensitive topics. The lead article on the Philippine reproductive health law, as discussed by a health advocate, former Department of Health Secretary Dr. Esperanza Cabral, conveys the challenges over years of discussions and arguments in a predominantly Catholic population. Trends on teenage pregnancy are reviewed by Dr. Josefina Natividad, Director of the University of the Philippines Population Institute.

Clinical Practice Guidelines (CPGs) in the region related to reproductive health are few. We feature the Myanmar and Indonesian Clinical Practice Guidelines for Diabetes Mellitus in Pregnancy and the Indonesian CPG for the Management of Thyroid Dysfunction During Pregnancy. Clearly, reproductive endocrinology issues are potential areas of research and collaboration among the countries of AFES.

Beginning this issue, we shall also feature brief reports on multi-disciplinary symposia elucidating challenging and often rare cases seen in endocrinology. The Philippine Society of Endocrinology and Metabolism (PSEM)'s Interhospital Grand Rounds on "Common Variable Immunodeficiency and Type 1 Diabetes Mellitus in a 19-year-old Filipino Male with Alopecia Universalis" provides an initial discussion on this topic with comments and summary from resource speakers.

JAFES is committed to promoting the sharing of knowledge and research findings. Towards this end, all articles published in the JAFES are open access to all, downloadable in PDF format at www.asean-endocrinejournal.org.

With the evolving trends in scholarly publishing, JAFES is transitioning to an online format. With plans of limiting the print copies to save on publication and shipment costs, we are exerting efforts to enhance our online presence through the website. We urge our readers to find time to browse through our enhanced website with its new features. We shall also soon embark on an improved journal management system to streamline the editorial process, from manuscript submission to online publication.

We have recently been recognized by the International ISSN in Paris, France with both a print and an electronic ISSN henceforth reflected in this and forthcoming issues and the website. These serial numbers are important to unequivocally identify our journal. Obtaining them are important first steps towards the JAFES' journey to indexing.

We are happy to report that we have been endorsed to the Asia-Pacific Association of Medical Editors (APAME) for inclusion in the WHO Western Pacific Region Index Medicus (WPRIM). We shall be formally included in the roster of medical journals of the WPRIM at the APAME Convention in Japan this coming August. Concurrently, JAFES has already submitted the requirements for indexing under Scopus and National Institutes of Health Medline. We are, therefore, looking forward to a wider coverage, reach and exposure of Southeast Asian research on endocrinology in the global arena.

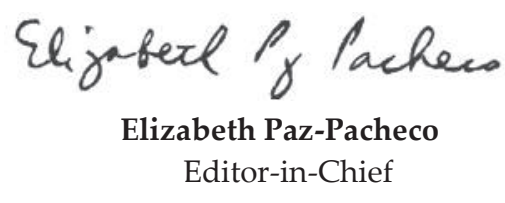

